\title{
Formalizing an empirical model: a way to enhance the communication between users and designers
}

\author{
Pierre-Emmanuel Arduin, Michel Grundstein, Elsa Negre and Camille Rosenthal-Sabroux \\ Université Paris-Dauphine, \\ LAMSADE, \\ Place du Maréchal de Lattre de Tassigny, F-75016 Paris, France \\ Email: pierre-emmanuel.arduin@lamsade.dauphine.fr, \\ mgrundstein@mgconseil.fr, \\ elsa.negre@lamsade.dauphine.fr, \\ camille.rosenthal-sabroux@lamsade.dauphine.fr
}

\begin{abstract}
This paper introduces a formalization of the Data, Information, Tacit and Explicit Knowledge process (DITEK) empirical model. This formalization reduces the gap between empirical and formal worlds, what led us to consider it as an opportunity to enhance the communication between users and designers of digital information systems. Notably, the designer will be aware of the role of the user as a component of the Enterprise's Information and Knowledge System (EIKS), defined in this paper.
\end{abstract}

We highlight how having two models, empirical and formal, for the same concept can constitute an outline in order (i) to enhance the communication between users and designers of digital information systems, (ii) to regard users as components of the EIKS, and (iii) to promote information systems' innovative design.

\section{INTRODUCTION}

Many people associate the term Knowledge Management (KM) with some kind of technological term. It is very often reduced to simple IT-based systems, which offer basic functionality to share the documents and informations among the employees of the company. It is based on a wrong assumption that knowledge can be gathered and managed in the same manner as informations - processed, transferred and stored. Knowledge can be very often mistaken with information. What is the difference then?

In the following, we introduce, Section II, the three postulates on which our researches rely on. Then, Section III, we present the user-centered Enterprise's Information and Knowledge System (EIKS) concept. Section IV details the differences between the concepts of data, information, tacit and explicit knowledge within DITEK and its formalized model is proposed. After discussion, Section V, the last section concludes this paper and presents our future work.

To do that research we have three motivations: First, we want to consolidate the Data, Information, Tacit and Explicit Knowledge process (DITEK) empirical model. We can insure that this empirical model is consistent and not ambiguous and can be described more precisely. Second, with a formalized model we improve the communication between people who work on a socio-technical and IT world. Usually these two worlds do not understand each others. Third, the formalized model can improve the commensurability of interpretative frameworks between users and designers.

\section{OUR THREE FUNDAMENTAL POSTULATES: RELATED WORKS}

For us, knowledge has to be considered as a crucial resource. [1] pointed out the necessity of considering company's knowledge as an essential resource and has announced a new challenge: "The challenge is to find out what you have - and use it". He even notices the fatal effects of "contents" oriented processes which were not subjected to advisability studies: "Companies waste billions on knowledge management because they fail to figure out what knowledge they need, or how to manage it." [2].

$\mathrm{KM}$ is often looked from a technological viewpoint, which leads to consider knowledge as an object and disregard the importance of people. To avoid this, in 2001, the CCRC ECRIN Working Group defines KM as follows: "KM is the management of the activities and the processes that enhance the utilization and the creation of knowledge within an organization, according to two strongly interlinked goals, and their underlying economic and strategic dimensions, organizational dimensions, socio-cultural dimensions, and technological dimensions: (I) a patrimony goal, and (II) a sustainable innovation goal.".

Our work relies on this definition of $\mathrm{KM}$ and on three postulates [3]: (A) Knowledge is not an object, (B) Knowledge is linked to the action, and (C) Company's knowledge includes two main categories of knowledge. These postulates are defined below.

\section{A. Knowledge is not an object}

When [4] introduces the concepts of sense-giving and sense-reading, we simply observe that we continuously appropriate information which is not ours. As the authors of this paper, we have got tacit knowledge that we have structured into information during a process of sense-giving. As the readers 


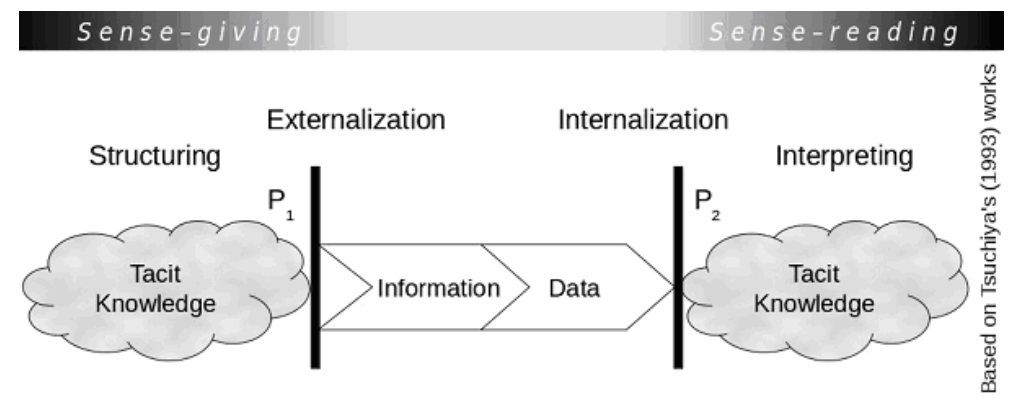

Fig. 1. Tacit knowledge transfer

of this paper, you have interpreted this information perceiving forms and colors, integrated words, data, during a process of sense-reading, possibly creating new tacit knowledge for you (see Figure 1). A person $\mathrm{P}_{1}$ creates information when he/she structures his/her tacit knowledge and externalizes it. A person $\mathrm{P}_{2}$ possibly creates new tacit knowledge when he/she perceives some data from this information and internalizes it. Knowledge is thus the result of the interpretation by someone of information, this interpretation is done through an interpretative framework [5].

If the probability that two people will give the same meaning to the same information is high, it is said that their interpretative frameworks have a strong commensurability or are commensurable. On the contrary, if this probability is low, it is said that their interpretative frameworks have a low commensurability or are incommensurable. Many of our studies aim at setting a mean to measure this commensurability.

So knowledge lies in the interaction between an interpretative framework (incorporated within the head of an individual, or embedded into an artifact) and data. This postulate is based on the theories that deal with the construction of tacit individual knowledge. According to this research, the tacit knowledge, which lies within one's brain, is the result of the meaning one allocates - through one's interpretative frameworks - to the data that one perceives as part of all the information received. This individual knowledge is tacit and it may or may not be expressed. It becomes collective knowledge as soon as it is shared by other individuals, whose interpretative frameworks are "commensurable", i.e. there is a minimal common level of interpretation, which is shared by all members of the organization.

\section{B. Knowledge is linked to the action}

[6] pointed out the limitations of technological systems which can "reinforce existing functional and geographical boundaries" ([6], p.94) within an organization and its intranet. Knowledge cannot be handled as an object otherwise all the tacit dimension will be neglected. That is notably the reason why [7] and [8] highlight that knowledge cannot be separated from its owner which is an individual. For them, whatever investments in data bases or information technologies, if individuals are not managed, knowledge is not fully managed.

From a business perspective, knowledge is created through action. Knowledge is essential for the functioning of business and projects processes, and is finalized through their activities. Hence, one has to be interested in the activities of the actors engaged in the processes contained in the company's missions. This vantage point is included in the use of the concept of knowledge, which cannot be separated from the individual placed within the company, his/her actions, decisions and relations with the surrounding systems (people and artifacts) [3].

\section{Company's knowledge includes two main categories of knowledge}

If [9] was the first to consider the existence of tacit knowledge when he said: "we can know more than we can tell", [10] pointed out the duality explicit/tacit as inherent to every individual and every organization. According to them, explicit knowledge being only the tip of the iceberg, tacit knowledge should not be neglected. [11] goes deeper with the idea of "knowledge revolution", which is inspired for him by the information systems, but need human systems to be realized ([11], p.116).

Within a company, knowledge consists in explicit knowledge on the one hand, composed of all tangible elements (we call it "know-how"), and on the other hand tacit knowledge, which includes intangible knowledge (we call it "skills"). The tangible elements are formalized in a physical form (databases, procedures, plans, models, algorithms, analysis and synthesis documents) and/or are embedded in automated management systems, conception and production systems, and in products. The intangible elements are inherent to the individuals who bear them, either as collective knowledge (the "routines" - non-written individual or collective action procedures) or as personal knowledge (skills, crafts, "job secrets", historical and contextual knowledge, environmental knowledge, competitors, technologies, socio-economic factors, etc).

Our researches based on these three postulates lead us to expand the concept of Information System into the one of Enterprise's Information and Knowledge System. 


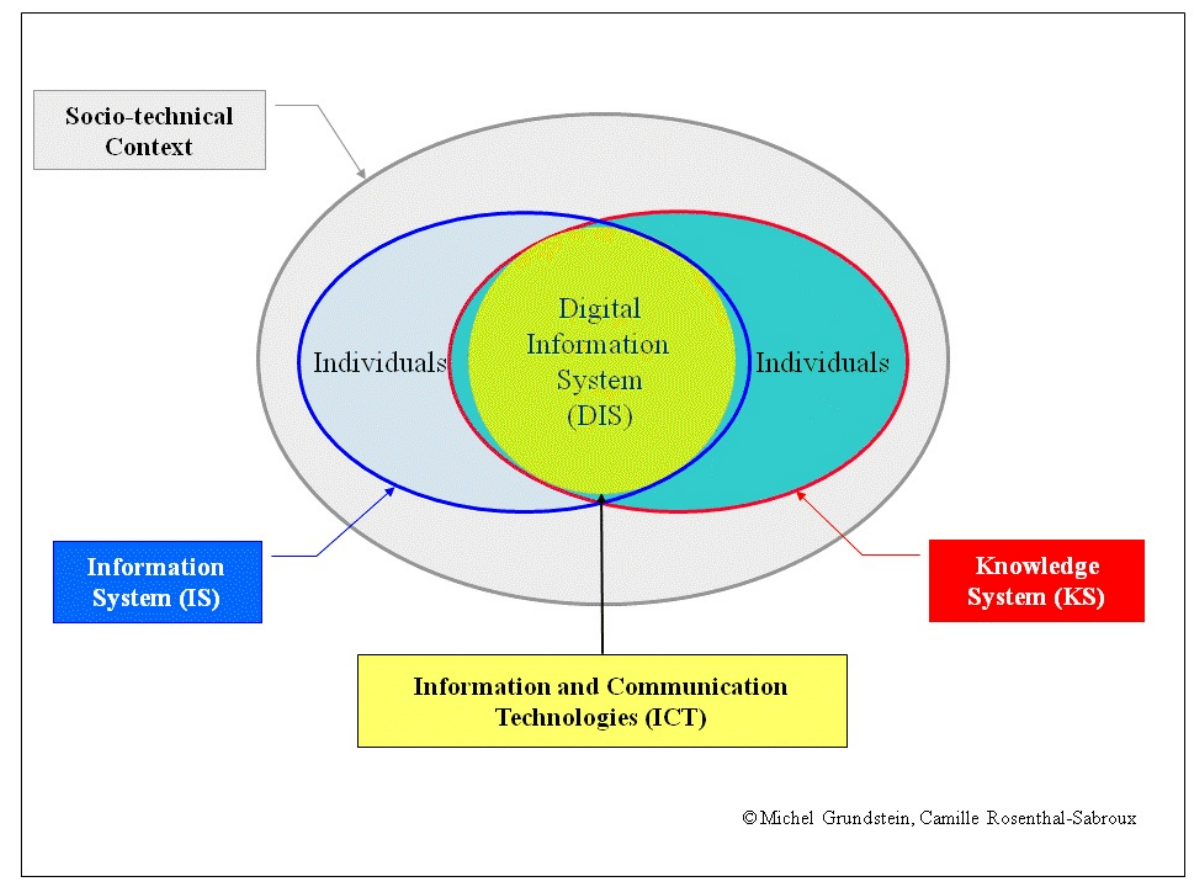

Fig. 2. The enterprise's information and knowledge system (EIKS)

\section{ENTERPRISE'S INFORMATION AND KNOWLEDGE SYSTEM - EIKS}

Enterprise's Information and Knowledge System (EIKS) consists mainly in a set of individuals and digital information systems (Figure 2).

EIKS rests on a socio-technical context, which consists of individuals in interaction among them, with machines, and with the very EIKS. It includes:

- A Digital Information Systems (DIS), which is artificial system, the artifact designed from information and communication technologies (ICT)

- An Information System (IS), constituted by individuals who, in a given context, are processors of data to which they give a sense under the shape of information. This information, depending of the case, is passed on, remembered, treated, and diffused by them or by the DIS.

- $\quad$ A Knowledge System (KS), consisting of tacit knowledge embodied by the individuals, and of explicit knowledge formalized and codified on any shape of supports (documents, video, photo, digitized or not). Under certain conditions, digitized knowledge is susceptible to be stored, processed and spread with the DIS. In that case, knowledge is no more than information.

We insist on the importance to integrate the individual as a user and a component of the EIKS as [12] highlighted in their study on Collaborative Knowledge Management System (CKMS) design. They emphasized that "One of the most important components of CKMS is the knowledge workers, who are also the users of the system, and the workspaces they are associated with" (p.172). In fact, relying on our assumptions, we argue that knowledge resides primarily in the heads of individuals, and in the social interactions of these individuals.

EIKS highlights the importance to distinguish data, information, tacit and explicit knowledge. That is described below in Data, Information, Tacit and Explicit Knowledge process (DITEK).

\section{DATA, INFORMATION, TACIT AND EXPLICIT KNOWLEDGE PROCESS - DITEK}

\section{A. The empirical model}

Numerous authors analyzed the notions of data, information and knowledge. Let us quote notably [13], [14], [15], [16]. Besides, [17] makes the following synthesis: "The developing practice of knowledge management has seen two different approaches to definition; one arises from information management and sees knowledge as some higher-level order of information, often expressed as a triangle progressing from data, through information and knowledge, to the apex of wisdom. Knowledge here is seen as a thing or entity that can be managed and distributed through advanced use of technology... The second approach sees the problem from a sociological basis. These definitions see knowledge as a human capability to act." ([17]).

The dominant positivism approach of $\mathrm{KM}$ is implicit in the DIKW (Data-Information-Knowledge-Wisdom) hierarchy model. This model induced numerous computers and information researches. For example, [18] revisiting the DIKW hierarchy by examining the articulation of the hierarchy in a number of widely read textbooks in information systems and knowledge management preferably published in 2003 and later, noted that "there is a consensus that data, information and 
knowledge are to be defined in terms of one another, although data and information can both act as inputs to knowledge; the tangle of concepts can be explored at two levels - the relationship between data and information, and the relationship between information and knowledge" ([18]) and she raised the question: "Is there a sharp divide between data, information and knowledge, or do they lie on a continuum with different levels of meaning, structure and actionability occurring at different levels?" ([18]).

In fact, we think that, beyond all these studies, we have to position our thoughts in the contextual field where the notion of data, information, and knowledge are used: in our case, the field of enterprises and more generally organizations. That leads to conceive how the transformation process should be, constructing the empirical model of DITEK, which is described below.

1) From data to information, and tacit and explicit knowledge: the DITEK empirical model: Relying on the theories and assumptions set out above, we elaborated a model that attempt to describe the transformation process from data to information, and from information to tacit and explicit knowledge. This model, called DITEK empirical model [19], describes at a first level the relationship between data and information, and at a second level the relationship between information, and tacit and explicit knowledge. Contrary to the idea of continuum between the concepts of data, information, and knowledge induced by the DIKW hierarchical model, DITEK empirical model shows a discontinuity between these concepts. In DITEK empirical model, by analogy with mental model ([20]), we highlight the function of interpretative framework as a filter that provides the mechanism through which data aggregated in a new information are filtered and processed by individual's tacit knowledge.

a) The first level: from data to information: At a first level, we have to consider the relationship between data and information. This level must be thought as a basic process where data are discrete raw elements perceived, gathered, and selected by a person before to be aggregated, supplemented, and organized into information. Let's describe the transformation process (see Figure 3).

At time $T_{0}$, a sender $P_{1}$ is acting in specific context and situation. $P_{1}$ possesses pre-existing interpretative frameworks, previous tacit knowledge, and intentions. In an information creation phase, $P_{1}$, has direct access to a set of data outside himself. Then, $P_{1}$ according to a sense-reading process - that depends of his pre-existing interpretative frameworks activated depending of his context, his situation, and his intentions, selects some of these data that take sense for him. At the same time, a sense-giving process using $P_{1}$ 's previous tacit knowledge enables $P_{1}$ to aggregate, supplement and organize selected data into information $\mathrm{I}\left(P_{1}, T_{0}\right)$. Once created this information becomes a static object independent from $P_{1}$, and time. It is this information that is passed-on by the individuals or by means of the digital information system (DIS) where it is stored, treated and transmitted as a stream of digital data. During this process, $P_{1}$ 's pre-existing interpretative frameworks are not changing; previous tacit knowledge can be reorganized and modified into new tacit knowledge that can change intentions. b) The second level: from information to tacit and explicit knowledge: At a second level, we have to consider the relationship between information, and tacit and explicit knowledge. This level is in rupture with the first one, it presupposes that information already exists whatever are time and context in which it was created. Let's describe the transformation process (see Figure 4 and 5).

At time $T_{n}$, a later stage of the first level process, when $P_{2}$ perceives the information $\mathrm{I}\left(P_{1}, T_{0}\right)$ during a reception, selfreflection and observation phase (see Figure 4), this information is captured by $P_{2}$, who is in different context and situation than $P_{1}$ who elaborates it. $P_{2}$ has his own intentions. Then, $P_{2}$ according to a sense-reading process interprets this information, filtering data through his pre-existing interpretative frameworks activated depending of his context, his situation, and his intentions. At the same time, a sense-giving process that uses $P_{2}$ 's previous knowledge operates, and engenders new tacit knowledge. That's the way that changes $P_{2}$ 's preexisting interpretative frameworks, and enriches $P_{2}$ 's previous tacit knowledge enabling $P_{2}$ to understand his situation, identify a problem, find a solution, decide, and act. The results of this process are modified interpretative frameworks, and new tacit knowledge. The process of transformation of information into tacit knowledge is a process of construction of knowledge. Created knowledge, can be very different from one individual to another when the commensurability of their interpretative frameworks is small, whatever are the causes of it. There are large risks that the same information takes different senses for each of them, and consequently generates a construction of different tacit knowledge in the head of the decision process stakeholders. Unlike the information, knowledge is dynamic. Once constructed it cannot be considered as an object independent from the individual who built it, or the individual who appropriates it to make a decision and to act.

Later on, at time $T_{n+1}$, when $P_{2}$ as a sender communicates with a receiver $P_{3}$, during a tacit knowledge articulation phase (see Figure 5), a sense-giving process enables $P_{2}$ to articulate a part of his new tacit knowledge into explicit knowledge that is no more than information $\mathrm{I}\left(P_{2}, T_{n+1}\right)$ for $P_{3}$.

As a result one can understand the importance to clearly distinguish static factual information, which allows describing the context and the situation that raise a problem, from the cognitive process engendered by the interpretative frameworks and the tacit knowledge possesses by the individual who processes this information to learn and get knowledge he needs to carry out his tasks. Consequently, paraphrasing [21] if technology provides the possibility of making information available across time and space, we always have to keep in mind the role of individual in the knowledge sharing process, but we do also pay attention to how individual uses technology to share knowledge. Our approach of KM induces to consider tacit and explicit knowledge as the outcome of a sense-giving process that involves people engaged in actions. It mainly 


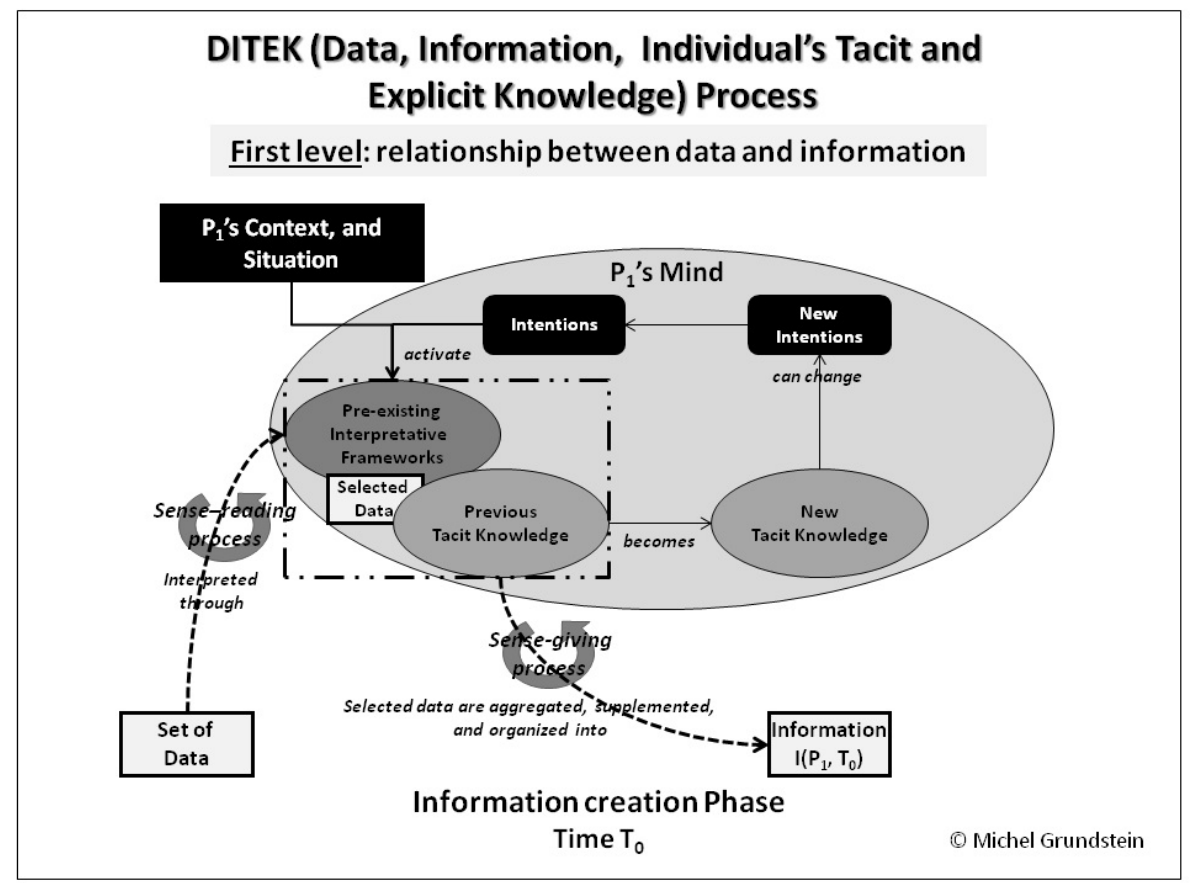

Fig. 3. DITEK empirical model level 1: From data... to information

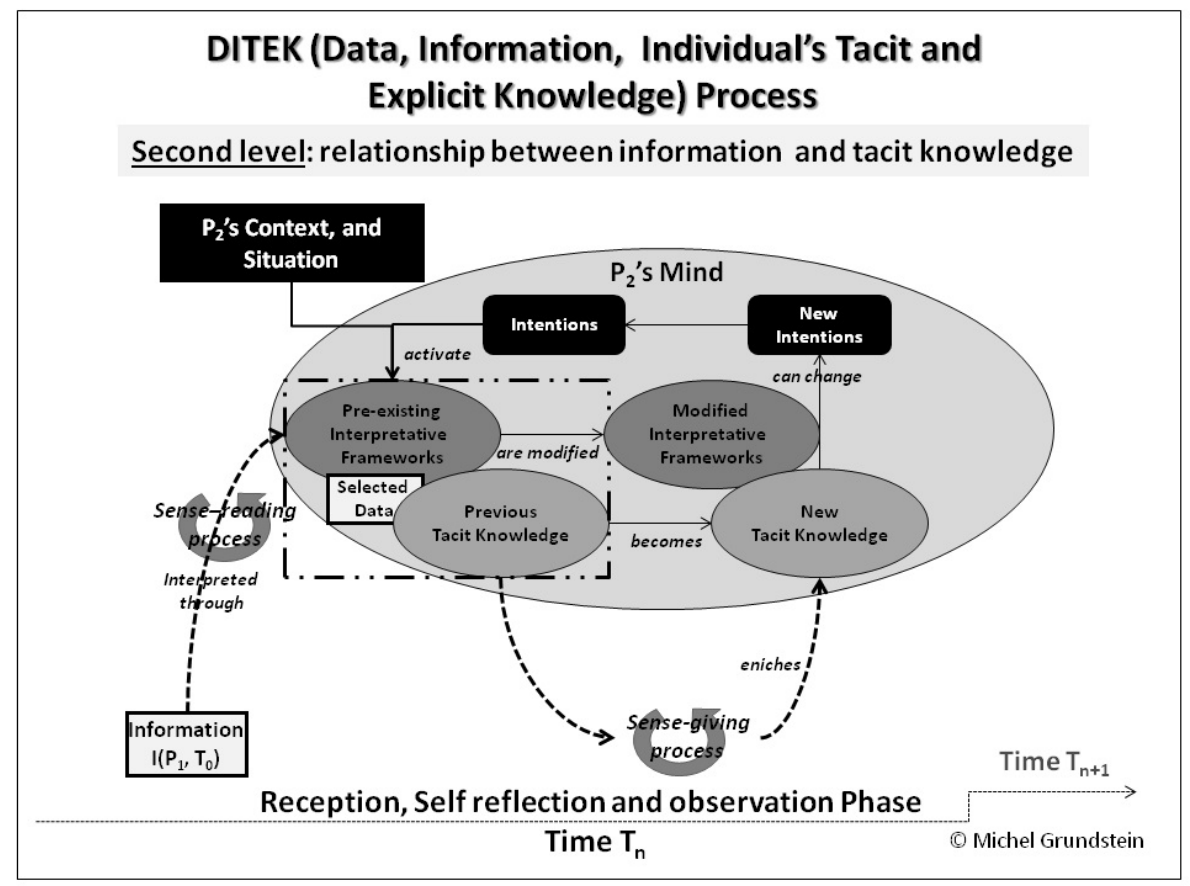

Fig. 4. DITEK empirical model level 2: From information... to tacit knowledge 


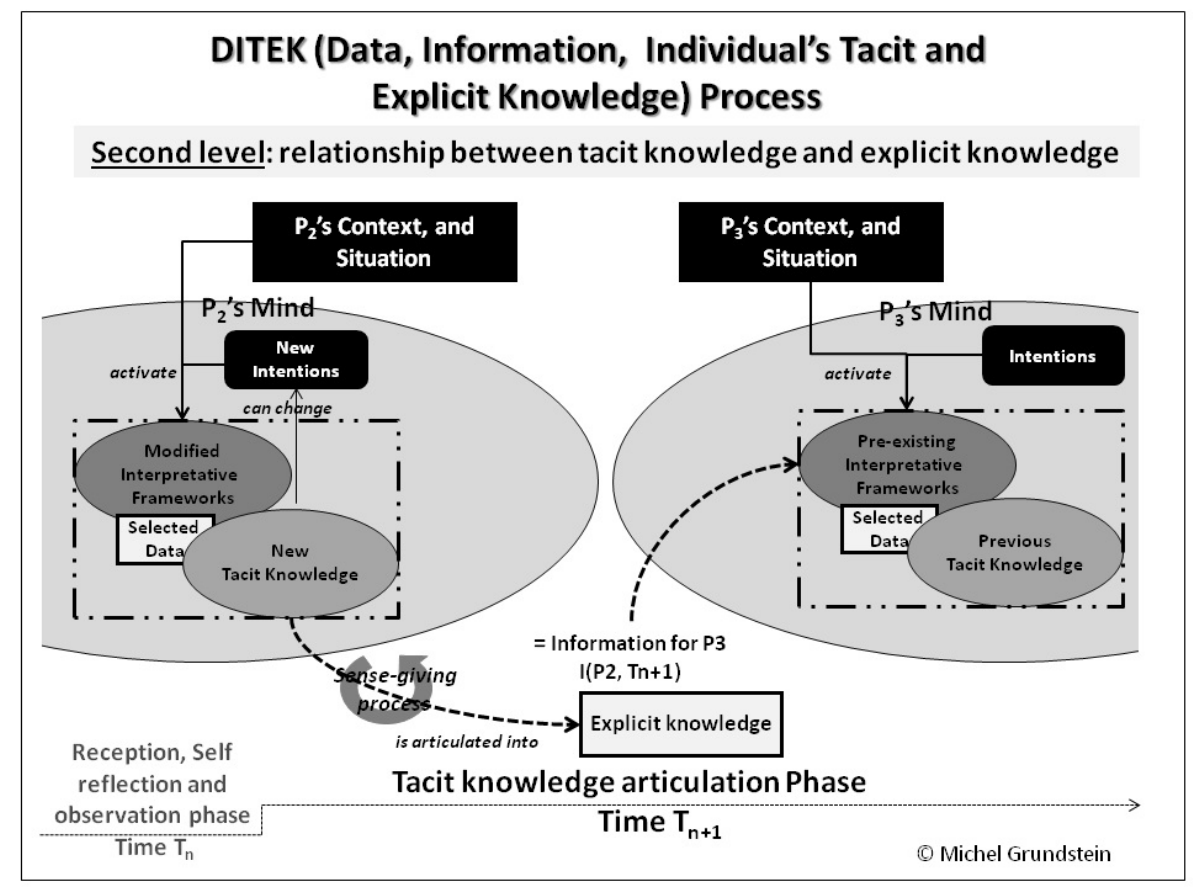

Fig. 5. DITEK empirical model level 2: From tacit knowledge... to explicit knowledge

depends of the economic and strategic, organizational, sociocultural, and technological, contexts.

\section{B. The formalized model}

As presented previously, the DITEK empirical model describes the relationship between data and information, and between information and knowledge (tacit and explicit). In this section, it is presented as a mathematical model (based on [19]). We agree with the idea that a mathematical model is a description of an observation using mathematical concepts and language. A such model may help to explain this observation and to study the effects of different components, and to make predictions about behavior. In general, mathematical models may include logical models, as far as logic is taken as a part of mathematics. In many cases, the quality of a scientific field depends on how well the mathematical models developed on the theoretical side agree with results of repeatable experiments. Lack of agreement between theoretical mathematical models and experimental measurements often leads to important advances as better theories are developed.

In our formalized model, which is a "translation" of our empirical model (no updates, no deletions, no adds), we distinguish events, actors and actions. This work relies on the research work of [22]. We illustrate our formalized model with a toy example dealing with a class of children who already know the numbers and learn how to add them. Each formula is illustrated through an extract of the global example which is detailed at the end of this section.

\section{1) Events: SET OF MOMENTS OF EVENTS}

The finite set of moments of events is $T=t_{0}, t_{1}, t_{2}, \ldots$ where each moment $t_{i}, \forall i \in \mathbb{N}$ represents an event of reception of data or information or creation of information in some environment (e.g. company). These moments can take place in a same time, however in the model we always distinguish the order of these events. For independent actions (e.g. creating new knowledge by different individuals) we do not loose generality, on the other hand actions which are dependent do not take place at the same moment.

In our example, when $t=0$ : the teacher starts his/her explanations about addition creating information, when $t=1$ : the children are listening, receiving this information and trying to understand.

\section{MULTISET OF DATASETS RECEIVED IN CERTAIN MOMENTS}

The multiset of datasets received in certain moments is $D=$ $\left\{d_{t}, t \in T_{D} \subseteq T\right\}$. The elements of a multiset do not need to be unique. The same data can be received by different people at different moments. Normal set would not be able to model the redundancy of the elements.

In our example, at moment $t=0, d_{0}=\emptyset$ because no data have been received by the children. At time $t=1, d_{1}$ contains data received by the children when the teacher explains, such as $d_{1}=\{$ Reminder of numbers, + operator, ... $\}$.

\section{MULTISET OF INFORMATIONS CREATED OR RECEIVED IN CERTAIN MOMENTS}

The multiset of informations created or received in certain moments is $I=\left\{i_{t}, t \in\left(T_{I C} \cup T_{I R}\right) \subseteq T\right\}$ where $T_{I R}$ are moments of informations reception and $T_{I C}$ are moments of informations creation.

In our example, at moment $t=0, i_{0}$ contains informations created by the teacher when he/she is explaining (speech, illustrations, movements,...) such as $i_{0}=$ \{"Good morning", ..."Addition relies on + operator", ..., $<1+1>$ (written on the blackboard), ...\}.

\section{CONSTRAINTS}

We define some constraints to ensure that two events do not 
take place at the same time (constraint $C_{1}$ ) and that in each moment some event takes place (Constraint $C_{2}$ ).

$C_{1}: T_{D} \cap T_{I R}=\emptyset, T_{D} \cap T_{I C}=\emptyset, T_{I C} \cap T_{I R}=\emptyset$

$C_{2}: T_{D} \cup T_{I R} \cup T_{I C}=T$.

2) Actors: NUMBER OF PERSONS

The number of all the people in the environment (e.g. company) is the given number: $n \in \mathbb{N}^{*}$.

In our example, there are 20 children and 1 teacher, so $n=21$.

FAMILY OF SETS OF INDIVIDUALS'INTERPRETATIVE FRAMEWORKS

The family of sets of individuals'interpretative frameworks is defined as $\mathbb{F}=\left\{F_{m, t}, m \in \mathbb{N}^{*}, m \leq n, t \in T\right\}$ where each person has a set of interpretative frameworks. This set $F_{m, t}$ evolves in time (when an individual takes part in events of information reception), this is the reason why it is identified not only by a person $m$ it belongs to, but also by a certain moment $t$.

In our example, for Peter $(m=5)$ who is known to have notably visual abilities to understand things, at the moment $t=0, F_{5,0}=\{$ visual abilities, ... $\}$. Listening and watching the explanations of the teacher leads him to understand additions so that, at the moment $t=1, F_{5,1}=F_{5,0} \cup\{$ ability to understand additions\}.

SET OF TACIT KNOWLEDGE OF INDIVIDUALS

The set of tacit knowledge of individuals is defined as $K=\left\{k_{m, t}, m \in \mathbb{N}^{*}, m \leq n, t \in T\right\}$. Similarly to interpretative frameworks, the state of individuals'knowledge $k_{m, t}$ also depends on a certain person $m$ and moment in time $t$.

In our example, for Peter $(m=5)$ and John $(m=6)$ who notably known numbers and animals, at the moment $t=0$, $k_{5,0}=k_{6,0}=\mathbb{N} \cup$ animals $\}$. Listening and watching the explanations of the teacher leads them to understand or not additions so that, at the moment $t=1$, for Peter who has understood $k_{5,1}=k_{5,0} \cup\{+\}$, whereas for John who has not understood $k_{6,1}=k_{6,0}$.

\section{SET OF CIRCUMSTANCES}

Circumstances are context, situation and intentions of the individual. The set of circumstances is $C=\left\{c_{m, t}\right.$, $\left.m \in \mathbb{N}^{*}, m \leq n, t \in T\right\}$. This set contains all the circumstances $c_{m, t}$ of the event in certain time $t$ connected with certain individual $m$.

In our example, Peter $(m=5)$ is known to be more attentive than John $(m=6)$, at the moment $t=0, c_{5,0}=\{$ attentive, $\ldots\}$ and $c_{6,0}=\{$ non-attentive, ... $\}$. Of course, circumstances will evolve during the lesson.

\section{FAMILY OF SETS OF INDIVIDUALS}

Let $\mathbb{P}$ be the family of sets $P_{m, t}, m \in \mathbb{N}^{*}, m \leq n, t \in T$, where $P_{m, t}$ represents the individual in general and is defined as follows: $P_{m, t}=\left\{F_{m, t}, k_{m, t}, c_{m, t}\right\}$. This set $P_{m, t}$ is made in order to simplify notation and emphasize, that in some actions all the three crucial elements (interpretative framework $F_{m, t}$, tacit knowledge $k_{m, t}$ and circumstances $c_{m, t}$ ) of individual are involved.

In our example, for Peter $(m=5)$, at the moment $t=0, P_{5,0}=\left\{F_{5,0}, k_{5,0}, c_{5,0}\right\}=\{\{$ visual abilities, $\ldots\},\{\mathbb{N} \cup$ $\{$ animals $\}\},\{$ attentive, ... $\}$ \}.

SET OF MOMENTS WHEN INDIVIDUALS WERE INVOLVED IN ACTION

Let $T_{m} \subseteq T, m \in \mathbb{N}^{*}, m \leq n$ represent a set of moments when the $m^{\text {th }}$ person was involved in action. $\forall m_{i}, m_{j} \in \mathbb{N}^{*}, m_{i} \leq$ $n, m_{j} \leq n, m_{i} \neq m_{j}, T_{m_{i}} \cap T_{m_{j}}=\emptyset$ and $\cup_{m_{k}=1}^{n} T_{m_{k}}=T$. Constraints above guarantee that in certain moment of time only one person is involved in event (action).

In our example, for Peter $(m=5), T_{5}$ are the moments when Peter is involved in an action, such as when the teacher is speaking, he is listening and watching.

3) Actions: In this subsection, we distinguish the three possible actions: 1 . Converting data to information and creation of information, 2. Reception of information and 3. Transfer of information. For each one, we define some functions and we explain its roll-out.

a) Converting data to information and creation of information: We define two functions: knowledge $e_{d}$ and information.

\section{KNOWLEDGE FUNCTION}

Let knowledge $e_{d}: D \times \mathbb{P} \rightarrow K$ be a function that enriches individual's tacit knowledge with the data (sense-reading process), the result of the function is knowledge of the individual enriched with received data.

\section{INFORMATION FUNCTION}

Let information : $P \rightarrow I$ be a function that creates information based on individual's tacit knowledge, interpretative frameworks and circumstances.

During this action (converting data to information and creation of information), individual $m$ receives data in moment $t$ such as $P_{m, t+1}=\left\{F_{m, t}\right.$, knowledge $\left._{d}\left(D_{t}, P_{m, t}\right), c_{m, t+1}\right\}$, $t \stackrel{\in}{\in} T_{D} \cap T_{m}$ and creates information based on it in moment $t+1$ such as $i_{t+1}=$ information $\left(P_{m, t+1}\right)$, $t+1 \in T_{I C} \cap T_{m}$. In this case, the state of individual is changed only with regard to circumstances, i.e., $P_{m, t+2}=\left\{F_{m, t+1}, k_{m, t+1}, c_{m, t+2}\right\}$.

In time $t$ individual $m$ is acting in the specific circumstances, has a certain state of interpretative framework and knowledge, which together are denoted as $P_{m, t}$. In an information creation phase, individual has direct access to some set of data (processed and prepared, data preparation is not a part of the model). The sense-reading process begins, in this process, data is transformed to tacit knowledge of the individual with use of his pre-existing knowledge and set of interpretative frameworks, which are activated by certain circumstances. During this process, pre-existing interpretative frameworks of individual are not changing. Previous tacit knowledge of individual is converted into a new tacit knowledge.

Then, in order to create information the will of an individual is necessary. This will is a part of circumstances. The new information is created based on circumstances, tacit knowledge of the individual and his interpretative frameworks. 
In our opinion, interpretative frameworks are necessary to create information as a kind of verification tool. When individual creates the information properly, it has to be created in such a way, that it would be an information source of knowledge for him. The fact whether or not something is information source of knowledge for an individual is connected with individuals' interpretative frameworks, though they are necessary in information creation phase. Once created, information becomes a static object, which is independent from its creator and can be stored, processed and transmitted to other individuals.

b) Reception of information: We define two functions: knowledge $_{i}$ and modification.

\section{KNOWLEDGE FUNCTION}

Let knowledge $e_{i}: I \times \mathbb{P} \rightarrow K$ be a function that enriches individual's tacit knowledge basing on received information, with use of self reflection and observation.

\section{MODIFICATION FUNCTION}

Let modification $: K \times \mathbb{F} \rightarrow \mathbb{F}$ be a function that modifies individual's interpretative frameworks based on new tacit knowledge, created with use of self reflection and observation.

During this action (reception of information), individual $m$ receives information in moment $t$ such as $P_{m, t+1}=\left\{\right.$ modification (knowledge $\left.e_{i}\left(i_{t}, P_{m, t}\right), F_{m, t}\right)$, knowledge $\left._{i}\left(i_{t}, P_{m, t}\right), c_{m, t+1}\right\}, t \in T_{I R} \cap T_{m}$.

Received information affects individual's tacit knowledge and interpretative frameworks, transition from moment $t$ (information reception) to moment $t+1$ (processing the information is finished) corresponds to observation and self reflection.

According to a sense-reading process, individual interprets the information $i_{t}$ with use of pre-existing interpretative frameworks $F_{m, t}$ activated depending on the circumstances, at the same time sense-giving process uses individual's preexisting knowledge and with use of interpreted information changes it into the new tacit knowledge. During this process also the set of interpretative frameworks is affected (some parts of information can affect it). It is worth to emphasize that the creation of new tacit knowledge and new set of interpretative frameworks are the processes which take place simultaneously. All in all, the results of these processes are modified: interpretative frameworks $F_{m, t+1}$, and new tacit knowledge $k_{m, t+1}$, which belong to $P_{m, t+1}$.

c) Transfer of information: In this phase, tacit knowledge is assimilated to explicit knowledge, which is nothing more than information. Thus, we use the function information : $P \rightarrow I$ to obtain the information for individual $m$ and the function knowledge $e_{i}: I \times \mathbb{P} \rightarrow K$ to obtain the knowledge of individual $w\left(m, w \in \mathbb{N}_{+}, m \leq n\right.$, $w \leq n, m \neq w)$.

During this action (transfer of information), knowledge is expressed by individual $m$ in time $t$ such as $i_{t}=$ information $\left(P_{m, t}\right), \quad t \in T_{I C} \cap T_{m}$ and knowledge is received by individual $w$ in time $t+1$ such as $P_{w, t+1}=\left\{\right.$ modification (knowledge $\left.e_{i}\left(i_{t}, P_{w, t}\right), F_{w, t}\right)$, knowledge $\left._{i}\left(i_{t}, P_{w, t}\right), c_{w, t+1}\right\}, t+1 \in T_{I R} \cap T_{w}$.

The process shows transfer of knowledge between two people through the information. It is important to distinguish static factual information, which allows describing the context and the situation from the tacit knowledge of the individual who processes this information to learn and get knowledge he needs to carry out his tasks. Knowledge is always connected to a person, it cannot exist separately. It is also important, that knowledge articulated into information from person $m$ in time $t$ can be totally different than knowledge received by person $w$ in time $t+1$. The more common set of interpretative frameworks of individuals $m$ and $w$, the more likely knowledge remains unchanged during the transfer.

4) Detailed example: Today is a special day for the children who already know the numbers: they will learn how to add them, they will learn the additions. We consider here a class of 20 children and their teacher so that $n=21$ is the number of all the people in the environment.

We remind that $P_{m, t}=\left\{F_{m, t}, k_{m, t}, c_{m, t}\right\}$ represents an individual $m \in \llbracket 1 ; 21 \rrbracket$ in a moment $t \in T$ with his interpretative frameworks $F_{m, t}$, his tacit knowledge $k_{m, t}$ and within certain circumstances $c_{m, t}$.

The teacher $P_{1, t}=\left\{F_{1, t}, k_{1, t}, c_{1, t}\right\}$ is a special individual because he already knows not only the numbers, but also how to add them. So that in the considered circumstances and at the beginning of the class, $k_{1,0}=\mathbb{N} \cup\{+\}$ is the set of his tacit knowledge. On the contrary, every children know the numbers and none of them know the additions, so that in the considered circumstances and at the beginning of the class, $k_{m, 0}=\mathbb{N}, m \in \llbracket 2 ; 21 \rrbracket$ is the set of tacit knowledge for every child.

At the moment $t=0$, when he is explaining how to operate additions, the teacher is creating information based on his tacit knowledge, interpretative frameworks and circumstances. $\mathrm{He}$ is using the function information defined above and he is creating the information $i_{0}=$ information $\left(P_{1,0}\right)$, the information created by the person 1 (the teacher) at the moment 0 (beginning of the class). The state of the teacher is changed only with regard to the circumstances, i.e. $P_{1,1}=\left\{F_{1,0}, k_{1,0}, c_{1,1}\right\}$.

The class is now $(t=1)$ divided into two categories of children: those who understood the information they perceived $\left(m_{A} \in A\right)$ and those who did not $\left(m_{B} \in B\right)$, with $A \cup B=\llbracket 2 ; 21 \rrbracket$. Here the functions knowledge $e_{i}$ and modification defined above are used. We remind that the first function enriches individual's tacit knowledge based on received information and the second function modifies individual's interpretative frameworks based on new tacit knowledge.

Then for every child $m_{A} \in A$, i.e. for every child having understood the teacher's explanation, his set of tacit knowledge becomes: $k_{m_{A}, 1}=$ knowledge $_{i}\left(i_{0}, P_{m_{A}, 0}\right)=\mathbb{N} \cup\{+\}$. Thus, his set of interpretative frameworks becomes: $F_{m_{A}, 1}=$ modification $\left(\right.$ knowledge $\left.e_{i}\left(i_{0}, P_{m_{A}, 0}\right), F_{m_{A}, 0}\right)=$ modification $\left(k_{m_{A}, 1}, F_{m_{A}, 0}\right)$. Finally, every child having understood the teacher's explanation can be characterized by: $P_{m_{A}, 1}=\left\{F_{m_{A}, 1}, k_{m_{A}, 1}, c_{m_{A}, 1}\right\}, \forall m_{A} \in A$. Interpretative frameworks, tacit knowledge and circumstances have changed. On the contrary, for every child $m_{B} \in B$, i.e. for every child having not understood the teacher's 


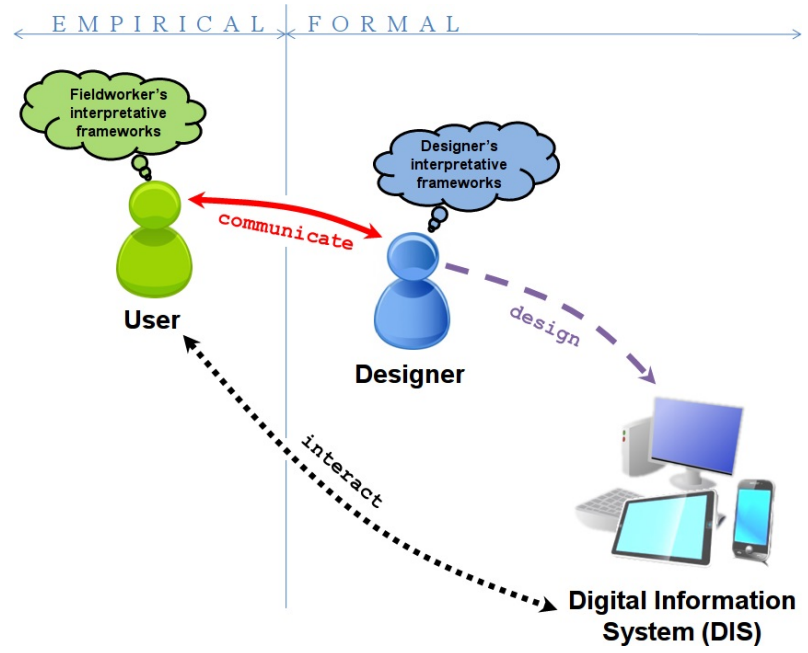

Fig. 6. Formalizing an empirical model: a way to enhance the communication between users and designers

explanation, his set of tacit knowledge will not change: $k_{m_{B}, 1}=$ knowledge $_{i}\left(i_{0}, P_{m_{B}, 0}\right)=\mathbb{N}=k_{m_{B}, 0}$. Thus, his set of interpretative frameworks will not change also: $F_{m_{B}, 1}=$ modification (knowledge $\left.e_{i}\left(i_{0}, P_{m_{B}, 0}\right), F_{m_{B}, 0}\right)=$ modification $\left(k_{m_{B}, 0}, F_{m_{B}, 0}\right) \quad=\quad F_{m_{B}, 0} \cdot \quad$ Finally, every child having not understood the teacher's explanation can be characterized by: $P_{m_{B}, 1}=\left\{\right.$ modification $\left.\left(k_{m_{B}, 0}, F_{m_{B}, 0}\right), k_{m_{B}, 0}, c_{m_{B}, 1}\right\}=$ $\left\{F_{m_{B}, 0}, k_{m_{B}, 0}, c_{m_{B}, 1}\right\}, \forall m_{B} \in B$. The state of this child $\left(m_{B} \in B\right)$ is changed only with regard to the circumstances.

\section{DISCUSSION}

In this section, we discuss the interest of our proposal (Figure 6).

As a first step, we propose to formalize the DITEK empirical model. Indeed, empirical modeling is more addressed to end-users while formal modeling is addressed to designers. Representing the same concepts with two equivalent models which cater to different actors, will help these actors to communicate. Our approach is illustrated Figure 6 where two persons having different interpretative frameworks tend to communicate. The aim for the designer is to design a digital information system relevant for the user. For that, the user has to explicit, at best, his expectations. Indeed, the user easily uses an empirical model to express his/her needs whereas the designer easily requires a formalized model to design a digital information system (DIS). Thus, our proposition of formalizing an empirical model leads these two persons not only to easily communicate but also to better understand each other. Therefore, the designer is able to design a DIS as closely as possible to the user's expectations. De facto, it enhances the interaction between the user and the system because it is relevant for his needs.

Finally, reducing the gap between empirical model and formal model is a way to enhance not only communication between users and designers, but also interaction between users and DIS. In our point of view, it constitutes a more innovative design.

In a second step, we include users into the EIKS. There- fore, we consider users, with their tacit knowledge and their interpretative frameworks, as components of the EIKS.

From these two previous points: (i) representing the same concepts with two equivalent models enhances the communication between users and designers, and (ii) considering users as components of the EIKS, we believe that formalizing an empirical model is an important step to a more innovative design of DIS.

\section{CONCLUSION AND FUTURE WORK}

The area of knowledge management in companies will not be replaced by strictly technological process for a very long time (until we will be able to read people's minds and copy their thoughts and ways of thinking, what the author hopes will never happen). It is very important to be aware of the processes connected with conversions between data, information and knowledge. DITEK presents these connections and allows on its basis to develop knowledge management strategies.

In this paper, we first present the three postulates that are the base of our researches. Then we introduce the usercentered EIKS concept. EIKS highlights the importance to distinguish data, information, tacit and explicit knowledge that is described in Data, Information, Tacit and Explicit Knowledge process (DITEK). The DITEK's formal model insures that the DITEK's empirical model is consistent and not ambiguous. We are well-aware, in the real world, with the formalized model, sometimes we do not have data for all the sets which may be empty.

Formalizing, particularly interpretative frameworks, tacit knowledge, and circumstances for several individuals, could sensitize to the diversity of individual understandings and could lead to their comparisons. In others words, this work in progress is a first step for measuring the commensurability of interpretative frameworks. 


\section{REFERENCES}

[1] T. A. Stewart, "Brain power: how intellectual capital is becoming America's most valuable asset," 1991.

[2] - The wealth of knowledge: Intellectual capital and the twenty-first century organization. New York: Currency, 2001.

[3] C. Rosenthal-Sabroux and M. Grundstein, "A global vision of information management," in Proceedings of the International Workshop on Model Driven Information Systems Engineering: Enterprise, User and System Models (MoDISE-EUS 08), 2008.

[4] M. Polanyi, "Sense-giving and sense-reading," Philosophy: Journal of the Royal Institute of Philosophy, vol. 42, no. 162, pp. 301-323, 1967.

[5] S. Tsuchiya, "Improving knowledge creation ability through organizational learning," in ISMICK 1993: Proceedings of the International Symposium on the Management of Industrial and Corporate Knowledge, 1993, pp. 87-95.

[6] S. Newell, H. Scarbrough, J. Swann, and D. Hislop, Managing Knowledge: Critical Investigations of Work and Learning. Macmillan, Basingstoke, 2000, ch. Intranets and knowledge management: de-centred technologies and the limits of technological discourse, pp. 88-106.

[7] G. Walsham, "Knowledge management: The benefits and limitations of computer systems," European Management Journal, vol. 19, no. 5, pp. 599-608, 2001.

[8] T. Wilson, "The nonsense of 'knowledge management'," Information Research, vol. 8, no. 1, 2002.

[9] M. Polanyi, Personal Knowledge: Towards a Post Critical Philosophy. Routledge, 1958.

[10] I. Nonaka and H. Takeuchi, The knowledge-Creating Company. Oxford University Press, 1995.

[11] R. Mc Dermott, "Why information technology inspired but cannot deliver knowledge management," California Management Review, vol. 41, no. 3, pp. 103-117, 1999.

[12] B. Chua and J. Brennan, "Enhancing collaborative knowledge management systems designs," in Proceedings 5th European Conference on Knowledge Management, 2004, pp. 171-179.

[13] T. Davenport and L. Prusak, Working Knowledge: How Organizations Manage What They Know. Harvard University Press, 1998.

[14] J. Sena and A. Shani, "Intellectual capital and knowledge creation: Towards an alternative framework," in Knowledge Management Handbook, J. Liebowitz, Ed. CRC Press, Boca Raton, FL, 1999, ch. 8, pp 8-1-8-16.

[15] A. Amin and P. Cohendet, Architectures of Knowledge: Firms, Capabilities, and Communities. Oxford, UK: Oxford University Press, 2004.

[16] J. Laudon and K. Laudon, Management Information Systems: Managing the Digital Firm (10th Edition), 2006.

[17] D. Snowden, "The social ecology of knowledge management," in Knowledge Horizons, C. Despres and D. Chauval, Eds. Boston: Butterworth-Heinemann, 2000, pp. 237-265.

[18] J. Rowley, "The wisdom hierarchy: representations of the dikw hierarchy," J. Information Science, vol. 33, no. 2, pp. 163-180, 2007.

[19] M. Grundstein, New Research on Knowledge Management Models and Methods. InTech, 2012, ch. Three Postulates That Change Knowledge Management Paradigm.

[20] N. A. Jones, H. Ross, T. Lynam, P. Perez, and A. Leitch, "Mental models: an interdisciplinary synthesis of theory and methods," Ecology and Society, vol. 16, pp. 1-13, March 2011.

[21] K. Kautz and A. Kjrgaard, "Towards an integrated model of knowledge sharing in software development: Insights from a case study," IJKM, vol. 3, no. 2, pp. 91-117, 2007.

[22] J. Szymczak, "Data, knowledge and information: Ditek process," Master's thesis, Université Paris-Dauphine, France, 2012. 